Article

\title{
Explaining Cannabis Use by Adolescents in Tarragona (Spain): Correlational and Fuzzy Set Qualitative Comparative Analyses
}

\author{
Jorge de Andres-Sanchez ${ }^{1 *}$, Angel Belzunegui-Eraso ${ }^{2}$
}

1 Social and Business Research Laboratory, Social Inclusion Chair, University Rovira i Virgili, jorge.deandres@urv.cat

2 Social and Business Research Laboratory, Social Inclusion Chair, University Rovira i Virgili, angel.belzunegui@urv.cat

* Correspondence jorge.deandres@urv.cat;

Abstract: The literature on substance use usually extracts conclusions from data with correlational methods. Our study shows the usefulness of complementing ordered logistic regression (OLR) and fuzzy set qualitative comparative analysis (fsQCA) to assess factors inducing cannabis consumption in a sample of 1,935 teenagers. OLR showed a significant influence of gender (odd ratio $(\mathrm{OR})=0.383$, $\mathrm{p}<0.0001)$, parental monitoring $(\mathrm{OR}=0.587, \mathrm{p}=0.0201)$; religiousness $(\mathrm{OR}=0.476, \mathrm{p}=0.006$ ); parental tolerance to substance use $(\mathrm{OR}=42.01, \mathrm{p}<0.0001)$ and having close peers that consume substances $(\mathrm{OR}=5.60, \mathrm{p}<0.0001)$. FsQCA has allowed fitting linkages between factors from a complementary perspective. (1) Coverage (cov) and consistency (cons) attained by solutions explaining use (cons $=0.808$, cov $=0.357$ ) are clearly lower than by recipes of non-use (cons $=0.952, \mathrm{cov}=0.869)(2)$ The interaction of gender, a tolerant family to use and the attitude toward substances by peers is very consistent to explain cannabis use. (3) The most important recipe explaining resistance to cannabis is simply parental disagreement with substance consumption (cons $=0.956$, cov=0.861) (4) Factors as gender, religiosity, parental monitoring and age show also a relevant impact on attitude toward cannabis use. However, whereas some of them impact symmetrically on use and non-use this does not follow in factors such as parental monitoring or age.

Keywords: adolescence; substance use; cannabis use; ordered logistic regression; fuzzy set theory; fuzzy set qualitative comparative analysis; Boolean functions.

\section{Introduction}

Cannabis (hashish or marijuana) are probably the most common consumed drugs around the world [1]. Early adolescence is a critical period of neurodevelopment, with synaptic pruning and increased myelination occurring. These processes are essential for the optimal development of cognitive, emotional, motivational and sensorimotor functions [2]. The use of cannabis by adolescents diminishes dramatically the skills needed to have an efficient learning process as attention or memory, but also has a physical impact on brain structure [3]. Simple searches in the Scopus database show that this issue is currently a relevant topic in public health research. On February 2, 2022, the search "cannabis AND adolescents AND factor AND use" showed 26 scientific documents in 2022 and 388 in 2021 and 440 in 2020. Although this result could be refined, we feel that these numerical results are convincing enough about the importance of this problem.

This paper evaluates factors that induce acceptance and rejection cannabis use and non-use by analyzing a survey from Tarragona (Spain) with more than 1,900 answers carried on within 2019. It is commonly accepted that there are a multitude of variables influencing substance use with complex interactions. These may be genetic, related to personality, or liked to differences in social circumstances and social responses [4].

Literature points out that undoubtedly there are several individual factors influencing substance use. Gender and age have been usually reported. So, being male is usually 
outlined as an enabler to drug consumption [5-18]. Likewise, the probability of using cannabis increases with adolescents' age [5, 8, 14, 17-20].

Adolescents' family environment often embeds several factors linked with substance consumption. Greater parental monitoring and support are related with a smaller probability of cannabis smoking [4,5,9-11,19-23]. Parental tolerance to substance use or parents' habitual consumption positively impacts on adolescent drug use [5,9,13,14,18,19,21,22]. Any adolescent spends most of his/her time in the school and with peers. Consequently, literature reports that school engagement; academic success and influence by friends are relevant factors to explain cannabis use. In this regard, whereas $[4,9,16,24]$ outline academic performance and engagement to school as a significant factor to explain drug consumption $[4,13,14,18,25-30]$ found decisive the behavior and attitude of peers toward substance use to explain cannabis consumption by teenagers.

There is a great deal of reports that indicates belonging to a religious community diminishes both the chances of acquiring substances and the opportunities to learn how to use them [31]. Nasim et al. [32] reported that religion has a dissuasive effect on the risk behaviors of adolescents, interfering with their use of drugs by helping them to internalize messages that discourage consumption. The significant protective effect of religiosity in cannabis smoking has been reported in samples from diverse cultures [4,5, 7,8,10,11,15,16,20,21,24,25,29,31-33].

All reviewed literature performs quantitative analysis using conventional correlational methods such as regression analysis. The novelty of this paper is the use of fuzzy set qualitative comparative analysis (fsQCA) displayed by Ragin [34,35] to complement results by ordered logistic regression (OLR). It must be outlined that the despite the use of fsQCA in public health sciences as is not new ([34,36] suggest its use in health research), it is not common at all and to the best of our knowledge, it has not been used in the assessment of adolescents'substance consumption.

In our study fsQCA and OLR are complementary rather than competitive since they allow the analysis of data from two non-excluding points of view.

1. Regression methods fit an analytical equation (usually linear or transformable into a linear equation) that quantifies the effect of input factors on the explained variable. On the other hand, fsQCA displays several combinations (or recipes) of input variables that may produce a given output by means of a Boolean function.

2. Regression analysis is a variable-oriented technique. Coefficients/odds ratios fitted with OLR measure net incidence of each input variable on output. On the other, fsQCA is case-oriented. It measures the membership degree of each case in the set of attributes and the outcome set by using fuzzy set union and intersection operators [37]. Thus, fsQCA does not quantify with a coefficient the influence of explanatory factors over the explained variable but discovers several ways how input variables combine to produce an output [38].

3. In regression analysis, an input variable can only be linked with output with one sign (positive or negative). The significance of this relation is measured with a so-called $\mathrm{p}$-value in such a way that these relations are usually considered relevant if $\mathrm{p} \leq 0.05$. On the other hand, fsQCA allows different signs for the influence of an input factor on their impact on the output variable in two combinations of explanatory variables. For example, as we have pointed out above, it is commonly accepted that religious activities have usually a protective capability towards cannabis use [25,29,31-33]. A configurational analysis may show that in some configurations the existence (nonexistence) of religiosity lead to non-use (use) of cannabis. However, it is also true that some kinds of spirituality may be an enabler of marijuana smoking [39-40]. This fact could induce configurations showing that the existence of a religious feeling is an explanatory condition of cannabis use in a piece of the sample.

4. Likewise-contrary to correlational methods - fsQCA does not assume symmetrical relationships between variables, despite being effective in that case [41]. This is relevant because combinations of factors that produce acceptance and rejection are possibly non-symmetrical. For example, perhaps having peers that are tolerant with 
cannabis use is an enabler to cannabis consumption but, on the other hand, this hypothetical fact does not imply that adolescents whose peers strongly disagree with cannabis use may have a symmetrical protective capability.

The study is developed as follows. In Section 2, we describe the material and methods used in our study. Subsequently, in section 3 , we present our results. We finally discuss our results and highlight principal conclusions.

\section{Materials and Methods}

\subsection{Sample and survey}

This cross-sectional study is based on the Planet Youth survey [42] and data collected from a structured questionnaire administered to secondary school students in Tarragona (Spain). The adolescents who completed the questionnaire were 15 years (54\%), 16 years (28.7\%) and 17 years (16.8\%) and $0.5 \%$ of responses were missed/refused. The $45.1 \%$ of sample responded that they were male, $52.4 \%$ responded that they were female and $3.5 \%$ refused to answer (responses were missed). The total number of adolescents interviewed was 1,935 (from a population universe of $N=2,407$ ). The data were collected between February and March 2019.

With the help of social workers of Tarragona city council we asked school head teachers for their permission and help with the survey. The questionnaire, which included the questions in Table 1, was completed online in roughly 15-20 minutes. After receiving permission from the adolescents and their guardians, teachers from the school checked that the adolescents understood the questions. Anonymity was fully ensured as it is impossible for us to know which adolescent provided which response and also his/her identity. Informed consent was requested in an email sent to the adolescents' parents or legal guardians asking that anyone who did not allow their child to take part should contact the school office to have them excluded from the study. The research was approved by authors' institution (CEIPSA-2021-PDR-39)

Table 2 provides a detailed description of relative frequencies of each possible response in every question. This table also shows the percentage of times the adolescents failed to provide an answer or preferred not to. After adjusted the sample due the existence of failed answers/refused questions we used 1,750 observations.

The input variable, cannabis use (USE), has 7 possible answers. It is explained by using seven explanatory variables that were motivated in introduction. Two of them are individual factors: gender (GENDER) and age (AGE). We also consider two variables linked to family environment: parental monitoring (MONITOR) and family tolerance to substance use (P_TOLER). Likewise, this paper also evaluates the impact of three variables linked to the adolescent's social circumstances: his/her disengagement to school (DSCHOOL), his/her engagement to religion (RELIGION) and friends' substance use and deviant behavior (PEER_USE). Table 1 shows the number of items that each variable contains and the Likert scale in which they were responded. Table 3 indicates the hypothetical impact of input variables on cannabis consumption based on literature reviewed in introduction. 
Table 1. Items of the questionnaire

\section{OUTPUT VARIABLE}

\begin{tabular}{cc} 
Cannabis use (USE): How often (if ever) have you used Cannabis (hashish or marijuana) last 30 \\
days? \\
\hline INPUT VARIABLES \\
\hline AENDER: Are you a boy or a girl? \\
AGE: What is your age? \\
\hline Disengagement to school (DSCHOOL). How well do the following statements apply to you? \\
(From 1=almost never to $5=$ almost always) \\
DSCHOOL1 $=$ & I find the school studies pointless \\
DSCHOOL2 $=$ & I am bored with the studies \\
DSCHOOL3 $=$ & I am poorly prepared for classes \\
DSCHOOL4 $=$ & I feel I do not put enough effort into the studies \\
DSCHOOL5 $=$ & I find the studies too easy \\
DSCHOOL6 $=$ & I find the studies too difficult \\
DSCHOOL7 $=$ & I feel bad at school \\
DSCHOOL8 $=$ & I want to quit school \\
DSCHOOL9 $=$ & I want to change the school \\
DSCHOOL10 $=$ & I get on badly with the teachers \\
\hline
\end{tabular}

Parental monitoring (MONITOR). How well do the following statements apply to you? (From $1=$ very poorly to $4=$ very well)

\begin{tabular}{|c|c|}
\hline MONITOR1= & My parents find it important that I do well in my studies \\
\hline MONITOR2= & My parents set definite rules about what I can do at home \\
\hline MONITOR3= & My parents set definite rules about what I can do outside \\
\hline MONITOR4= & My parents set definite rules about when I should be home in the evening \\
\hline MONITOR5= & My parents know whom I am with in the evenings \\
\hline MONITOR6= & My parents know where I am in the evenings \\
\hline MONITOR7= & My parents know my friends \\
\hline MONITOR8= & My parents know the parents of my friends \\
\hline MONITOR9= & My parents often talk to the parents of my friends \\
\hline MONITOR10= & $\begin{array}{c}\text { My parents and the parents of my friends sometimes meet to talk to one an- } \\
\text { other }\end{array}$ \\
\hline MONITOR11= & My parents follow what I do in my recreational time \\
\hline \multicolumn{2}{|c|}{$\begin{array}{l}\text { Religiousness (RELIGION). How well do the following statements apply to you? (From 1=very } \\
\text { poorly to } 4=\text { very well) }\end{array}$} \\
\hline RELIGION1= & I believe in God \\
\hline RELIGION2= & My faith is important to me \\
\hline RELIGION3= & I pray to god on a regular basis \\
\hline RELIGION4= & I regularly read in the scriptures of my faith \\
\hline RELIGION5= & I regularly attend religious services \\
\hline RELIGION6= & I regularly take part in religious activities other \\
\hline RELIGION7= & I would be able to get support from god if I needed \\
\hline RELIGION8= & I have sought support from god when I have needed i \\
\hline RELIGION9= & My best friends are religious \\
\hline RELIGION10= & Most of my acquaintances are religious \\
\hline RELIGION11= & My mother (foster/stepmother) is religious \\
\hline
\end{tabular}


RELIGION12=

My father (foster/stepfather) is religious

Tolerance padres/legal guardians (P_TOLER). How do you think your parents would react if you did any of the following? (From $1=$ Totally against to $4=$ not care)

$P_{-}$TOLER1 $=$ If you would smoke cigarettes

$P_{-}$TOLER2=

If you would become drunk

P_TOLER3=

If you would smoke cannabis

\begin{tabular}{|c|c|}
\hline \multicolumn{2}{|c|}{$\begin{array}{l}\text { Substance use by peers (PEER_USE): How many peers/friends do you think do the fol- } \\
\text { lowingy? (From } 1=\text { none to } 5=\text { almost all) }\end{array}$} \\
\hline PEER_USE1= & Smoke cigarettes \\
\hline PEER_USE2= & Drink alcohol (beer, wine, or spirits) \\
\hline PEER_USE3= & Become drunk at least once a month \\
\hline PEER_USE4= & Smoke hash or marijuana \\
\hline PEER_USE5= & Pick fights or search out for fights \\
\hline
\end{tabular}

Table 2. Response relative frequency of every question in the survey (in percentages)

\begin{tabular}{|c|c|c|c|c|c|c|}
\hline \multicolumn{7}{|c|}{ USE (OUTPUT VARIABLE) } \\
\hline $1=$ Never & $\begin{array}{l}2=" 1-2 \\
\text { times" }\end{array}$ & $\begin{array}{l}3=" 3-5 \\
\text { times" }\end{array}$ & $\begin{array}{l}4=\text { "6-9 } \\
\text { times" }\end{array}$ & $\begin{array}{c}5=\text { " } 10-19 \\
\text { times" }\end{array}$ & $\begin{array}{c}6=\text { " } 20-39 \\
\text { times" }\end{array}$ & $\begin{array}{c}7=" 40 \\
\text { times or } \\
\text { more" }^{\text {mor }}\end{array}$ \\
\hline $65.96 \%$ & 7.40 & 4.10 & 2.80 & 3.00 & 2.10 & 5.70 \\
\hline \multicolumn{7}{|c|}{ INPUT VARIABLES } \\
\hline Applies: & $\begin{array}{c}1=\text { almost } \\
\text { never }\end{array}$ & $2=$ seldom & $3=$ sometimes & $4=$ often & $\begin{array}{c}5=\text { almost al- } \\
\text { ways }\end{array}$ & failed/refused \\
\hline DSCHOOL1 & 30.6 & 26.6 & 24.7 & 10.2 & 4.7 & 3.3 \\
\hline DSCHOOL2 & 12.5 & 24.2 & 30.4 & 18.6 & 11.1 & 3.3 \\
\hline DSCHOOL3 & 34.8 & 28.8 & 18.2 & 8.9 & 5.6 & 3.7 \\
\hline DSCHOOL4 & 15.3 & 21 & 27.1 & 20.3 & 12.7 & 3.5 \\
\hline DSCHOOL5 & 28.8 & 31.7 & 23.6 & 8.5 & 3.8 & 3.7 \\
\hline DSCHOOL6 & 14.7 & 26.1 & 32.1 & 17.2 & 6.5 & 3.4 \\
\hline DSCHOOL7 & 58 & 16.2 & 10.7 & 6.5 & 4.8 & 3.8 \\
\hline DSCHOOL8 & 68.1 & 10.7 & 8 & 4.4 & 4.8 & 4.1 \\
\hline DSCHOOL9 & 63.6 & 11.5 & 8.9 & 5.3 & 7 & 3.8 \\
\hline DSCHOOL10 & 48.3 & 26.2 & 12.9 & 5.3 & 3.9 & 3.4 \\
\hline Applies: & $\begin{array}{l}1=\text { very } \\
\text { poorly }\end{array}$ & $2=$ poorly & $3=$ well & $\begin{array}{c}4=\text { very } \\
\text { well }\end{array}$ & failed/refused & \\
\hline MONITOR1 & 0.8 & 2.1 & 18.7 & 75.1 & 3.4 & \\
\hline MONITOR2 & 3.6 & 15.5 & 44.9 & 32.5 & 3.6 & \\
\hline MONITOR3 & 6 & 19.1 & 41.8 & 28.6 & 4.4 & \\
\hline MONITOR4 & 6.1 & 16.6 & 35.8 & 37.5 & 3.9 & \\
\hline MONITOR5 & 3.4 & 8.1 & 26 & 58.3 & 4.1 & \\
\hline MONITOR6 & 2.6 & 7.4 & 23.4 & 62.3 & 4.2 & \\
\hline MONITOR7 & 2.3 & 8.5 & 34.3 & 50.9 & 4 & \\
\hline MONITOR8 & 8.5 & 25.2 & 38.8 & 23.4 & 4.1 & \\
\hline
\end{tabular}




\begin{tabular}{|c|c|c|c|c|c|c|}
\hline MONITOR9 & 19.5 & 30 & 32.2 & 14.3 & 4 & \\
\hline MONITOR10 & 34.8 & 31.2 & 19.9 & 10 & 4.1 & \\
\hline MONITOR11 & 19.1 & 27.9 & 32.1 & 16.9 & 4 & \\
\hline Applies: & $\begin{array}{l}1=\text { very } \\
\text { poorly }\end{array}$ & $2=$ poorly & $3=$ well & $\begin{array}{c}4=\text { very } \\
\text { well }\end{array}$ & failed/refused & \\
\hline RELIGION1 & 49.7 & 15.1 & 12 & 14.9 & 8.3 & \\
\hline RELIGION2 & 43.5 & 16.8 & 13.3 & 17.6 & 8.8 & \\
\hline RELIGION3 & 63.3 & 13.1 & 6.6 & 7.8 & 9.3 & \\
\hline RELIGION4 & 72.2 & 8.7 & 5.5 & 4.7 & 8.9 & \\
\hline RELIGION5 & 70 & 10.1 & 5.2 & 5.9 & 8.8 & \\
\hline RELIGION6 & 70.2 & 10.7 & 4.7 & 5.3 & 9.1 & \\
\hline RELIGION7 & 57.9 & 12.5 & 10.6 & 9.7 & 9.2 & \\
\hline RELIGION8 & 52.6 & 14.4 & 12.1 & 11.8 & 9.1 & \\
\hline RELIGION9 & 49.1 & 24.8 & 11.1 & 5.5 & 9.5 & \\
\hline RELIGION10 & 41 & 25.3 & 17.3 & 7.1 & 9.4 & \\
\hline RELIGION11 & 43.4 & 14 & 13.9 & 19.1 & 9.7 & \\
\hline \multirow[t]{2}{*}{ RELIGION12 } & 49.6 & 12.9 & 12.7 & 14.8 & 10 & \\
\hline & $\begin{array}{c}1=\text { totally } \\
\text { against }\end{array}$ & $\begin{array}{c}2=\text { much } \\
\text { against }\end{array}$ & $\begin{array}{c}3=\text { rather } \\
\text { against }\end{array}$ & $\begin{array}{l}4=\text { not } \\
\text { care }\end{array}$ & failed/refused & \\
\hline P_TOLER1 & 58.9 & 15.7 & 10.3 & 4.8 & 10.2 & \\
\hline P_TOLER2 & 42.4 & 18.3 & 20.6 & 7.9 & 10.8 & \\
\hline \multirow[t]{2}{*}{ P_TOLER3 } & 73.9 & 9.7 & 3.6 & 1.9 & 10.9 & \\
\hline & $1=$ none & $2=a$ few & $3=$ some & $4=$ most & $5=$ almost all & failed/refused \\
\hline PEER_USE1 & 23 & 22.5 & 24.6 & 12.7 & 5.9 & 11.3 \\
\hline PEER_USE2 & 15.7 & 14.9 & 20.9 & 22.5 & 14.7 & 11.3 \\
\hline PEER_USE3 & 25.2 & 20.5 & 21.8 & 13.5 & 7.5 & 11.4 \\
\hline PEER_USE4 & 36.4 & 23 & 16.4 & 7.9 & 4.9 & 11.4 \\
\hline PEER_USE5 & 59.8 & 17.4 & 7.8 & 1.9 & 1.5 & 11.6 \\
\hline
\end{tabular}

Table 3. Hypotheses used to find intermediate solutions

\begin{tabular}{cc}
\hline Variable & Hypothesis about the influence on cannabis use \\
\hline GENDER & Females tend to consume less cannabis than males: \\
AGE & Older ages are more exposed to cannabis consumption \\
DSCHOOL & Disengagement to school is linked with cannabis use \\
MONITOR & A greater parental monitoring is linked with non-use \\
RELIGION & Religiousness has been found to be a protective factor against use. \\
P_TOLER & Family tolerance to substance use is linked with cannabis consumption. \\
PEER_USE & Peers' use and conduct deviance is linked with substance use. \\
\hline
\end{tabular}




\subsection{Analytical procedure}

\subsubsection{Statistical analysis}

Previous to apply fsQCA we perform a conventional statistical analysis of the impact of assessed factors on cannabis consumption as follows:

Step 1: We measure the reliability of variables DSCHOOL, MONITOR, RELIGION, P_TOLER, PEER_USE scales by using Cronbach's alpha.

Step 2: We define input variables in terms of membership functions, in such a way that for the $i$ th variable, $X_{i}$, the value of the $j$ th observation $x_{i, j}$ is transformed to $m_{X_{i, j}}$ as follows:

GENDER=Dichotomous variable that takes 0 for males and 1 for females.

AGE $=$ Variable that takes $0,0.5$ and 1 if the respondent is 15 years, 16 years and 17 years old, respectively.

As far as multiple item variables as DSCHOOL, MONITOR, RELIGION, P_TOLER and PEER_USE are concerned; we summed the evaluations on each item of these factors. It is a simple but usual way to deal with this question in empirical research [43]. Subsequently, we obtain the membership evaluation of these variables by using a common procedure in fsQCA [41].

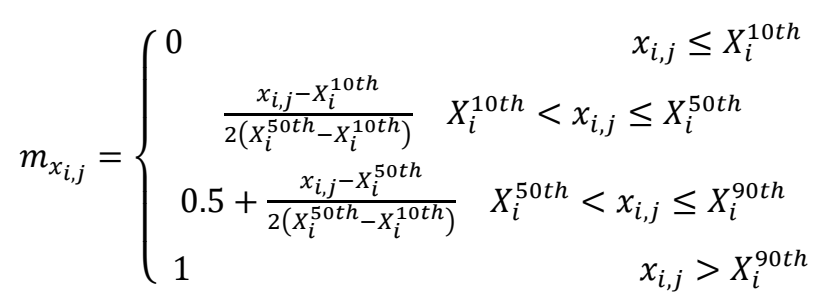

being $X_{i}^{\text {sth }}$ the sth quantile in the sample of $i$ th variable.

Step 3. We ran the contrarian case analysis described in [41], that will allow also stating a preliminary sign and statistical significance of the impact of input variables on USE. In this step, the values of input variables are those defined in step 2. The input variable (USE) is quantified by simply taking its value on the Likert scale in Table 1 and 2. Subsequently, we divide the sample by using quintiles of variables and then build up crosstabulations of USE with respect to input variables across these quintiles. Crosstabs allow stating the main effect between every input on output and its statistical significance, but also the existence of cases outside of the main effect that justify a configurational analysis. In this regard, Pappas and Woodside [41] advice using Phi measure to measure the weight of observations out of principal relation. A $\mathrm{Phi}^{2}<0.5$ suggests the existence a number of cases enough to justify a configurational analysis.

Step 4. We fit the output with an ordered linear regression (OLR) model. Whereas USE is defined in a Likert scale that ranges from 1 to 7 (see Table 1), input variables are quantified following step 2.

\subsubsection{Fuzzy set Qualitative Comparative analysis}

We perform fsQCA by following the following steps:

Step 1. Membership functions of input variables are those defined in step 2. For output variable USE, we define:

$$
m_{U S E_{j}}=\left\{\begin{array}{cc}
1 & y_{j} \geq 5 \\
0.9 & y_{j}=4 \\
0.8 & y_{j}=3 \\
0.2 & y_{j}=2 \\
0 & y_{j}=1
\end{array}\right.
$$

Step 2. We implement fsQCA with fsQCA 3.1 software [44]. It enables finding logical implications that fit output results by running a Boolean minimization algorithm. If we symbolize the negation of a variable as " $\sim$ ", we independently adjust the Boolean functions: 
$\sim$ USE=f(GENDER,AGE,DSCHOOL,MONITOR, RELIGION, P_TOLER, PEER_USE) (4)

Therefore, (3) explains intention to get vaccinated and (4) explains non-intention. At this regard, it must be outlined that the membership degree in the negated variable, $\sim X_{i}$, is $m_{\sim X_{i j}}=1-m_{X_{i j}}$. So, for $\sim \mathrm{USE}$ we state $m_{\sim U S E_{j}}=1-m_{U S E_{j}}$

The adjustment of USE and USE is done with the Quine-McCluskey algorithm to find essential prime implicates (configurations or recipes) in the truth table. These implicates conform to the so-called qualitative comparative analysis complex solution (CS).

Step 3. CS is usually hard to interpret since it is built up with no more assumptions than data. Therefore, fsQCA 3.1 also offers a parsimonious solution (PS). It is fitted by applying the Quine-McCluskey algorithm and any remainder over a non-observed configuration of variables to make the solution as easy as possible [35].

Step 4. To continue the minimization process, it must be supposed for non-observed configurations if an input variable contributes to output exclusively when it is present, absent or in both cases by using well-founded hypotheses. This step allows us to obtain the so-called intermediate solution (IS) [35]. In our paper we use the hypotheses in Table 3 that are supported by mainstream of literature reports exposed in introduction.

To consult an in-deep explanation of Boolean minimization procedures in CS, PS and IS see [45].

Step 5. To measure the explanatory power of a given recipe, its consistency (cons) and coverage (cov) must be calculated. Let be a possible prime implicate (configuration or recipe) $Z$ that without a loss of generality we built as:

$$
Z=X_{1} * X_{2} * \ldots * X_{r}
$$

where $1 \leq r \leq n, n$ is the number of output variables and "**" stands for the Boolean product. So, we can obtain for the $j$ th observation:

$$
m_{Z_{j}}=\min \left\{m_{X_{1, j}} ; m_{X_{2, j}} ; \ldots ; m_{X_{r, j}}\right\}
$$

Therefore, the consistency of recipe $Z$ in producing an output $Y$ is:

$$
\operatorname{Cons}_{Z \rightarrow Y}=\frac{\sum_{j} \min \left\{m_{Z_{j}} ; m_{Y_{j}}\right\}}{\sum_{j} m_{Z_{j}}}
$$

Subsequently, the coverage of recipe $Z$ to produce $Y$ is:

$$
\operatorname{Cov}_{Z \rightarrow Y}=\frac{\sum_{j} \min \left\{m_{Z_{j}} ; m_{Y_{j}}\right\}}{\sum_{j} m_{Y_{j}}}
$$

Consistency measures the membership degree of a combination of causes (a recipe) within the outcome set. It is similar to a statistical measure of significance [46]. There is a wide consensus that to consider an essential prime implicated as a sufficient condition, cons $>0.75$ (or better cons $>0.8$ ). Coverage measures the proportion of outcomes explained by a recipe, i.e., it is a measure of empirical relevance similar to $\mathrm{R}^{2}$ [46].

Step 6. To assess how input variables and their combinations impact on acceptance and rejection to cannabis use, solutions from fsQCA must be interpreted. There is no unified point of view about what solution (CS, PS or IS) to take into account. CS uses only empirical data, but the recipes in that solution are often hard to interpret. In this regard, [41] proposes combining both IS and PS to state core (from PS) and peripheral (present only in IS) conditions. 


\section{Results}

\subsection{Results of statistical analysis}

When validating the scales (Table 4), we checked that all constructs presented a Cronbach alpha $>0.7$. Thus, we have robust evidence on the internal consistency of DSCHOOL, MONITOR, RELIGION, P_TOLER, PEER_USE. So, in subsequent analysis these variables are defined following (1). The $10^{\text {th }}, 50^{\text {th }}$ and $90^{\text {th }}$ quantiles needed to fit (1) are displayed by Table 4 .

Table 4 also shows that values attained by the Phi measure showed a significant relation of USE with all explanatory variables $(\mathrm{p}<0.0001$ in all cases except for RELIGION where $\mathrm{p}=0.0001$ ). Kendall's Tau-b correlation indicates a positive (negative) linkage of AGE, P_TOLER, PEER_USE (GENDER, DSCHOOL, MONITOR, RELIGION) with USE where $\mathrm{p}<0.0001$ in all the cases.

Results of OLR in Table 5 allow nuancing results in Table 4 . We found that the ordered logit model was significant (pseudo $\mathrm{R}^{2}=48.27 \%$, LR statistic=2002, $\mathrm{p}<0.0001$ ). Notice that a pseudo $\mathrm{R}^{2}$ greater than $25 \%$ in an ordered logistic regression context can be qualified as excellent [47]. We checked a significant negative average influence of being female (odd ratio $(\mathrm{OR})=0.383, \mathrm{p}<0.0001$ ), MONITOR (OR=0.587, $\mathrm{p}=0.0201$ ); RELIGION (OR=0.476, $\mathrm{p}=0.0006)$; and a significant positive influence of perceiving that family does not care with substance use $(O R=42.01, p<0.0001)$ and PEER_USE $(O R=5.60, p<0.0001)$. The sign of the relation of AGE and DSCHOOL is that fitted with Tau-b correlation, but did not show statistical significance.

Table 4. Cronbach's alfa of scales, measures of association between independent variables and use and $10 \%, 50 \%$ and $90 \%$ quantiles of variables DSCHOOL, MONITOR, RELIGION, P_TOLER and PEER_USE

\begin{tabular}{ccccccccc}
\hline & $\begin{array}{c}\text { Cron- } \\
\text { bach- } \boldsymbol{\alpha}\end{array}$ & Phi & p-value & Tau-b & $\begin{array}{c}\text { p-va- } \\
\text { lue }\end{array}$ & $\begin{array}{c}\mathbf{1 0 \% -} \\
\text { quan- } \\
\text { tile }\end{array}$ & $\begin{array}{c}\mathbf{5 0 \% -} \\
\text { quan- } \\
\text { tile }\end{array}$ & $\begin{array}{c}\mathbf{9 0 \% -} \\
\text { quan- } \\
\text { tile }\end{array}$ \\
\hline GENDER & & 0.125 & $<0.0001$ & -0.101 & $<0.0001$ & & & \\
AGE & & 0.173 & $<0.0001$ & 0.165 & $<0.0001$ & & & \\
DSCHOOL & 0.769 & 0.166 & $<0.0001$ & -0.127 & $<0.0001$ & 28 & 39 & 45 \\
MONITOR & 0.799 & 0.243 & $<0.0001$ & -0.197 & $<0.0001$ & 15 & 22 & 29 \\
RELIGION & 0.928 & 0.121 & 0.001 & -0.089 & $<0.0001$ & 12 & 17 & 34 \\
P_TOLER & 0.753 & 0.931 & $<0.0001$ & 0.749 & $<0.0001$ & 3 & 3 & 9 \\
PEER_USE & 0.884 & 0.5 & $<0.0001$ & 0.396 & $<0.0001$ & 5 & 11 & 18 \\
\hline
\end{tabular}

Table 5. Ordered logistic regression estimates

\begin{tabular}{cccc}
\hline & Odd-ratio & z-ratio & p-value \\
\hline GENDER & 0.383 & -6.471 & $<0.0001$ \\
AGE & 1.168 & 0.7049 & 0.4809 \\
DSCHOOL & 0.755 & -1.175 & 0.2402 \\
MONITOR & 0.587 & -2.325 & 0.0201 \\
RELIGION & 0.476 & -3.415 & 0.0006 \\
P_TOLER & 42.010 & 18.79 & $<0.0001$ \\
PEER_USE & 5.600 & 6.232 & $<0.0001$ \\
\hline \multicolumn{4}{c}{ LR ratio=2002.91 $(\mathrm{p}<0.0001)$} \\
\hline & Pseudo $\mathrm{R}^{2}=48.26 \%$ &
\end{tabular}




\subsection{Results of $f \mathrm{~s} Q C A$}

Table 4 shows the results of Phi measure from contrarian case study. With the exception of parental tolerance, all linkages between input factors and substance use attain $\mathrm{Phi}^{2}<0.5$. This fact could indicate that there exist a significant number of cases that fail out of the mainstream relation and therefore it is justified the convenience of a configuration analysis by means of fsQCA [41].

Table 6. fsQCA solutions of USE and USE

\begin{tabular}{|c|c|c|c|c|c|c|c|c|}
\hline \multirow[b]{2}{*}{ factor / recipe } & \multicolumn{4}{|c|}{ USE } & \multicolumn{4}{|c|}{ NON-USE ( USE) } \\
\hline & 1 & 2 & 3 & 4 & factor $\mid$ recipe & 1 & 2 & 3 \\
\hline GENDER & $\otimes$ & $\otimes$ & $\otimes$ & $\otimes$ & GENDER & & - & - \\
\hline AGE & & - & & - & AGE & & & $\bullet$ \\
\hline DSCHOOL & & & $\otimes$ & & DSCHOOL & & $\otimes$ & \\
\hline MONITOR & & & - & $\otimes$ & MONITOR & & $\bullet$ & $\bullet$ \\
\hline RELIGION & $\otimes$ & & & $\otimes$ & RELIGION & & • & • \\
\hline P_TOLER & - & $\bullet$ & $\bullet$ & - & P_TOLER & $\otimes$ & & \\
\hline PEER_USE & $\bullet$ & $\bullet$ & - & & PEER_USE & & $\otimes$ & $\otimes$ \\
\hline cons & 0.831 & 0.819 & 0.774 & 0.787 & cons & 0.956 & 0.949 & 0.941 \\
\hline cov & 0.260 & 0.300 & 0.173 & 0.127 & $\mathrm{cov}$ & 0.861 & 0.135 & 0.137 \\
\hline cons of IS & 0.808 & & & & cons of IS & 0.952 & & \\
\hline cov of IS & 0.357 & & & & cov of IS & 0.869 & & \\
\hline
\end{tabular}

Note: A full circle $(\bullet)$ indicates the presence of a condition, and circles with $\mathrm{x}(\otimes)$ indicate its absence.

Table 6 shows the results of fsQCA for use and non-use of cannabis. At this regard we must outline that CS, IS and PS of use and also in non-use are the same. It can be checked that non-use is clearly better explained than use. Consistency is 0.952 in non-use vs 0.808 in use and coverage attains 0.869 in non-use and 0.357 in use.

As far as USE is concerned, we can check that:

- Configurational analysis detects that the confluence of being male and perceiving a parental tolerance toward the use of substances is present in all explanatory configurations. It is also very relevant the presence of PEER_USE (3 over 4 recipes).

- The absence of religiousness and being older is a condition in two prime implicates of USE.

- Parental monitoring is present with contradictory sign in two recipes. Third recipe shows a group of adolescents whose cannabis use is explained with the confluence of high parental monitoring and other variables. However, there also exists a part of responses acknowledging cannabis smoking that can be explained by the confluence of low parental monitoring with other factors (fourth recipe).

- The absence of DSCHOOL, than can be understood as a well-being in school, is present in one configuration explaining use.

Regarding the configurations fitted for non-users, we observe the following patterns:

- Perceiving a great disagreement toward substance use by family is sufficient condition to be a non-consumer (cons $=0.956$, $\operatorname{cov}=0.861$ ).

- McCluskey algorithm identifies two more prime implicates with a great cons $(\approx 0.95)$ but limited coverage $(<0.15)$ that are not linked with attitude of family toward substance. In these prime implicates being female, having a high parental monitoring, religiousness and the absence of PEER_USE must be present with non-disengagement to school (in the second recipe) and greater ages (in the third). 


\section{Discussion}

In this paper we have used ordered logistic regression (OLR) and fuzzy set Qualitative Comparative Analysis (fsQCA) to assess factors of that may explain adolescents' use of cannabis (USE).

OLR model provided a very good adjustment of USE (pseudo R2>48\%). Being female (GENDER), a high parental implication in adolescent activities (MONITOR) and religiousness (RELIGION) have a significant protective impact against cannabis smoking habits. Parent or legal guardians' liberal attitude toward substance consumption (P_TOLER) and peers habitual use of substance and conduct deviance (PEER_USE) suppose a significant risk of cannabis smoking. OLR does not detect a significant impact of age (AGE) and adolescents' disengagement to school (DSCHOOL) into USE.

The fact that being male is a significant risk factor of cannabis use is in accordance with mainstream findings in literature [5-18]. The significant and negative relation of MONITOR with USE is widely supported by literature [4,5,9-11,19-23], that found similar results for the influence of parental monitoring on drug consumption. Analogous conclusion it is extracted from OLR finding on the impact of RELIGION over USE and reviewed literature $[4,5,7,8,10,11,15,16,20,21,24,25,29,31-33]$.

As we expected, our results display a positive and significant influence of P_TOLER and PEER_USE on USE. Whereas in the case of P_TOLER our results confirm those in $[5,9,13,14,18,19,21,22]$ our findings over PEER_USE are in the line of $[4,13,14,18,25-30]$.

The application of fsQCA on data analysis allows extracting complementary conclusions from sample. We have observed that the proposed models to explain acceptance and rejection to cannabis consumption present an asymmetric adjustment capability. Whereas resistance to cannabis is extremely well explained (cons $=0.95$ and cov $=0.86$ ), cannabis use attains an acceptable consistency (cons=0.80) and not so great coverage (cov=0.3). So the very great OLR determination coefficient is because factors have much capability to explain cannabis non-use but less to explain use.

The results of fitting USE and $\sim$ USE with fsQCA also allow detecting the nuances of the impact on consumption by input variables. The parental attitude toward substance use is the key factor in adolescents' cannabis smoking habit. However, the impact of

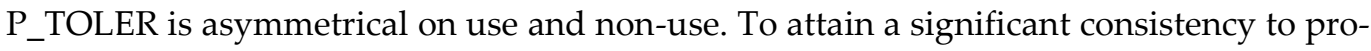
duce use, $\mathrm{P}_{-}$TOLER always needs to be combined with being female and, depending on the configuration, with variables as, e.g. PEER_USE, RELIGION. On the other hand, the absence of $\mathrm{P}_{-}$TOLER is a sufficient condition to reject cannabis consumption.

The other factor linked to adolescent parental circumstance, MONITOR is relevant to explain cannabis use, but much less relevant than parental. This finding is consistent with [19] that report so. Likewise, whereas the sign of MONITOR is not unique when takes part of explanatory recipes of USE (it appears in two different recipes affirmed and negated), it shows a consistent positive relation with non-use (it is present in two recipes explaining non-use). Therefore, the sign of MONITOR in OLR can be produced basically by its impact over cannabis non-use.

The presence of AGE is necessary in two recipes explaining USE. That is to say, fsQCA links positively older ages with cannabis consumption. This is in accordance with $[5,8,14,17-20]$. However, notice that this impact is asymmetrical on non-use since AGE is also present in a recipe explaining that behaviour.

GENDER, RELIGION and PEER_USE also exhibit a consistent sign in their relation with cannabis consumption. GENDER, RELIGION (PEER_USE) are always negated (affirmed) in the explanatory prime implicates of USE and affirmed (negated) when induce cannabis rejection. Likewise, GENDER and PEER_USE participate in more explanatory recipes of use and non-use than RELIGION. Therefore, we can consider the impact of these variables on cannabis consumption as symmetrical.

To the best of our knowledge, combinatorial analysis of variables that induce acceptance and unwillingness to substance use by adolescents has not been done. This paper shows that fsQCA not only helps to understand how input variables influence 
consumption and inhibition to cannabis smoking but also that some of the assessed factors impact asymmetrically on use and non-use. These findings have fair potential implications for health policies. On one hand, we have identified several adolescents' profiles that are consistently linked with cannabis smoking. In these profiles are always present males and parental tolerance to substance consumption but also, depending on the profile, absence of religious engagement, relationship with peers that also use substances, or they are aged teenagers. Likewise, it seems that parental attitude toward substances is the keystone to explain use and non-use. This fact suggests that cannabis prevention campaigns by health policy makers must be addressed not only to adolescents but also to their families. The most important protective factor to cannabis smoking habits is a strong parental intolerance toward substance use.

This study is based on a cross-sectional survey. Although our conclusions about the impact of assessed factors generally reinforce findings in other countries, further research will require longitudinal data to assess the directionality of the influences. We have also feel relevant to point out that Tarragona is a city of near 150,000 citizens whose main economic activities are industry and services with a relevant part of migrant population from Magreb and Latin America. Therefore, the results could be representative for similar social environments in Spain such as cities within the area of influence of Barcelona or Madrid. On the other hand, we believe that the results cannot be transferred to adolescents in rural Spanish regions whose main activity is the primary sector or tourism and have a low proportion of immigrant citizens.

Author Contributions: Conceptualization, Angel Belzunegui-Eraso; Methodology, Jorge de Andrés-Sánchez; Software, Jorge de Andrés-Sánchez; Formal analysis, Jorge de Andrés-Sánchez; Angel Belzunegui-Eraso; Investigation, Angel Belzunegui-Eraso; Data Curation, Angel Belzunegui-Eraso; Writing Original Draft, Jorge de Andrés-Sánchez; Angel Belzunegui-Eraso; Writing - Review \& Editing: Jorge de Andrés-Sánchez, Angel Belzunegui-Eraso; Visualization, Jorge de Andrés-Sánchez; Supervision, Angel Belzunegui-Eraso; Funding acquisition, Angel Belzunegui-Eraso.

Funding: This paper is a result of the research project "Prevention of drug use and gambling in adolescents: the information paradox. The case of Tarragona" that has been funded by $<<$ Ministerio Español de Ciencia e Innovación, Plan nacional R+D+I 2019>>. Code: PID2019-104310RB-C21

Data Availability Statement: Available by demanding it to authors.

Conflicts of Interest: Authors declare no conflict of interests.

Ethical Statement: (1) all participants and their legal guardians were informed about the study and procedure; (2) anonymity of the data collected was ensured at all times; (3) the study was carried on with the permission and support of Tarragona Council through its Committee for the Prevention of Addictions and Catalonian Department of Education and has been approved by the Ethical Committee of University Rovira i Virgili (code: CEIPSA-2021-PDR-39) (4) completion of the questionnaire was voluntary for children after obtaining permission by head school and their legal guardians. 


\section{References}

1. Peacock. A., Leung, J.; Larney, S.; Colledge, S.; Hickman, M.; Rehm, J.; Degenhardt L. Global statistics on alcohol, tobacco and illicit drug use: 2017 status report. Addiction 2018, 113, 1905-1926. http://dx.doi.org/ 10.1111/add.14234.

2. Hawke, LD.; Henderson, J. Legalization of cannabis use in Canada: Impacts on the cannabis use profiles of youth seeking services for substance use. Journal of substance abuse treatment 2021, 126, 108340. https://doi.org/10.1016/j.jsat.2021.108340.

3. Jacobus J, Bava S, Cohen-Zion M, Mahmood O, Tapert SF. Functional consequences of marijuana use in adolescents. Pharmacol Biochem Behav. 2009 92, 559-565. http://dx.doi.org/10.1016/j.pbb.2009.04.001

4. Sutherland, I., Shepherd, J. P. Social dimensions of adolescent substance use. Addiction 2001, 96, 445-458. http://dx.doi.org/10.1046/j.1360-0443.2001.9634458.x

5. Kliewer, W., Murrelle, L. Risk and protective factors for adolescent substance use: findings from a study in selected Central American countries. Journal of adolescent health 2007, 40, 448-455. https://doi.org/10.1016/j.jadohealth.2006.11.148

6. Sutherland, I., \& Willner, P. Patterns of alcohol, cigarette and illicit drug use in English adolescents. Addiction 1998, 93, 11991208. http://dx.doi.org/1199-1208. 10.1046/j.1360-0443.1998.93811998.x

7. Francis, J. M., Myers, B., Nkosi, S., Petersen Williams, P., Carney, T., Lombard, C., \& Morojele, N. The prevalence of religiosity and association between religiosity and alcohol use, other drug use, and risky sexual behaviours among grade 8-10 learners in Western Cape, South Africa. PloS One 2019, 14, e0211322. https://doi.org/10.1371/journal.pone.0211322.

8. Raposo, J. C.D.S., Costa, A. C. D. Q., Valença, P. A. D. M., Zarzar, P. M., Diniz, A. D. S., Colares, V., \& Franca, C. D. Binge drinking and illicit drug use among adolescent students. Revista de Saude Publica 2017, 51, 83. https://doi.org/10.11606/S15188787.2017051006863.

9. Rasic, D., Kisely, S., \& Langille, D. B. Protective associations of importance of religion and frequency of service attendance with depression risk, suicidal behaviours and substance use in adolescents in Nova Scotia, Canada. Journal of Affective Disorders 2011, 132, 389-395. https://doi.org/10.1016/j.jad.2011.03.007.

10. Andres-Sanchez, J., Belzunegui-Eraso, A., \& Fernández-Aliseda, S.. Religion as a Protective Factor against Adolescent Smoking Habits: Evidence from Spain. Christian Journal for Global Health 2021, 8, 16-23. https://doi.org/10.15566/cjgh.v8i2.579

11. Bartkowski, J. P., \& Xu, X. Religiosity and teen drug use reconsidered: A social capital perspective. American Journal of Preventive Medicine 2007, 32, S182-S194. http://doi.org/10.1016/j.amepre.2007.03.001

12. Carvajal, S. C., Hanson, C. E., Romero, A. J., \& Coyle, K. K. Behavioural risk factors and protective factors in adolescents: A comparison of Latinos and non-Latino whites. Ethnicity $\mathcal{E}$ Health 2002, 7, 181-193. https://doi.org/10.1080/1355785022000042015

13. Butters, J.E. The impact of peers and social disapproval on high-risk cannabis use: gender differences and implications for drug education. Drugs: Education, Prevention and Policy 2004, 11, 381-390, http://dx.doi.org/10.1080/09687630410001704437

14. Larrosa, S. L., \& Rodríguez-Arias, J. L. Risk factors and protection against drug consumption by adolescents and differences due to sex and age. Psicothema 2010, 22, 568-573.

15. Parenteau, S. Religious Coping and Substance Use: The Moderating Role of Sex. Journal of Religion and Health 2015, 56, 380-387. http://doi.org/10.1007/s10943-015-0166-7

16. Piko, B. F., \& Fitzpatrick, K. M. Substance use, religiosity, and other protective factors among Hungarian adolescents. Addictive Behaviours 2004, 29, 1095-1107. https://doi.org/10.1016/j.addbeh.2004.03.022

17. Sinha, J., Cnaan, R., \& Gelles, R. Adolescent risk behavior and religion: findings from a national study. Journal of Adolescence 2007, 30, 231-249. http://dx.doi.org/10.1016/j.adolescence.2006.02.005

18. Libuy, N.; Carlos Ibáñez, A.; Mundt, P. Factors related to an increase of cannabis use among adolescents in Chile: National school based surveys between 2003 and 2017, Addictive Behaviors Reports 2020 11, 100260. https://doi.org/10.1016/j.abrep.2020.100260.

19. Parsai M, Kulis S, Marsiglia FF. Parental Monitoring, Religious Involvement and Drug Use Among Latino and Non-Latino Youth in the Southwestern United States. Br J Soc Work. 2010, 40, 100-114. https://doi.org/10.1093/bjsw/bcn100

20. Kim-Spoon, J., Farley, J. P., Holmes, C., Longo, G. S., \& McCullough, M. E. Processes linking parents' and adolescents' religiousness and adolescent substance use: Monitoring and self-control. Journal of Youth and Adolescence 2014, 43, 745-756. https://doi.org/10.1007/s10964-013-9998-1

21. McArdle, P., Wiegersma, A., Gilvarry, E., Kolte, B., McCarthy, S., Fitzgerald, M. \& Quensel, S. European adolescent substance use: the roles of family structure, function and gender. Addiction 2002, 97, 329-336. https://doi.org/10.1046/j.13600443.2002.00066.x

22. Badr, L.K., Taha, A. \& Dee, V. Substance Abuse in Middle Eastern Adolescents Living in Two Different Countries: Spiritual, Cultural, Family and Personal Factors. Journal of Religion and Health 2014, 53, 1060-1074. https://doi.org/10.1007/s10943-013-96941

23. Gmel G, Mohler-Kuo M, Dermota P, Gaume J, Bertholet N, Daeppen JB, Studer J. Religion is good, belief is better: religion, religiosity, and substance use among young Swiss men. Subst Use Misuse 2013 48, 1085-98. https://doi.org/10.3109/10826084.2013.799017. PMID: 24041170.

24. Jeynes, W. H. Adolescent religious commitment and their consumption of marijuana, cocaine, and alcohol. Journal of Health and Social Policy 2006, 21, 1-20. https://doi.org/10.1300/J045v21n04_01 
25. Ford, J. A., \& Hill, T. D.. Religiosity and Adolescent Substance Use: Evidence from the National Survey on Drug Use and Health. Substance Use \& Misuse, 2012, 47, 787-798. https://doi.org/10.3109/10826084.2012.667489

26. Adamczyk, A., \& Palmer, I. Religion and initiation into marijuana use: the deterring role of religious friends. Journal of Drug Issues 2008, 38, 717-742. https://doi.org/10.1177/002204260803800304.

27. Bahr, S., \& Hoffmann, J.. Religiosity, peers, and adolescent drug use. Journal of Drug Issues 2008, 38, 743-770. https://doi.org/10.1177/002204260803800305

28. Moriarty, J., \& Higgins, K. Effects of peer network interactions on adolescent cannabis use. Journal of Criminal Psychology 2015, 5, 75-91. https://doi.org/10.1108/JCP-01-2015-0003

29. Thomas, NS, Salvatore, JE, Gillespie, NA, Aliev, F, Ksinan, AJ, Dick, DM; Spit for Science Working Group. Cannabis use in college: Genetic predispositions, peers, and activity participation. Drug Alcohol Depend 2021, 219.108489. https://doi.org/10.1016/j.drugalcdep.2020.108489.

30. Tucker JS, de la Haye K, Kennedy DP, Green HD Jr, Pollard MS. Peer influence on marijuana use in different types of friendships. J Adolesc Health 2014, 54, 67-73. https://doi.org/10.1016/j.jadohealth.2013.07.025

31. Hill, T., Burdette, A.,Weiss, M., Chitwood, D. Religious involvement and adolescent substance use. In Adolescent substance abuse: evidence-based approaches to prevention and treatment; Leukefeld, C., Gullotta, T., Staton-Tindall M., Eds.; Springer: Switzerland, 2009; pp. 171-189. https://doi.org/10.1007/978-0-387-09732-9

32. Nasim, A., Utsey, S. O., Corona, R., \& Belgrade, F. Z. Religiosity, refusal efficacy, and substance use among African-American adolescents and young adults. Journal of Ethnicity in Substance Abuse 2006, 5, 29-49. https://doi.org/10.1300/J233v05n03_02

33. Buchtova, M.; Malinakova, K.; Kosarkova, A.; Husek, V.; van Dijk, J.P.; Tavel, P. Religious Attendance in a Secular Country Protects Adolescents from Health-Risk Behavior Only in Combination with Participation in Church Activities. Int. J. Environ. Res. Public Health 2020, 17, 9372. https://doi.org/10.3390/ijerph17249372.

34. Ragin, C.C. Using qualitative comparative analysis to study causal complexity. Heal. Serv. Res. 1999, 34, 1225-1239.

35. Ragin, C.C. Redesigning Social Inquiry: Fuzzy Sets and Beyond. Chicago University Press: Chicago, IL, USA. 2008.

36. Lee, S. S.-Y. "Using fuzzy-set qualitative comparative analysis." Epidemiology and health 2014 , 36. https://doi.org/10.4178/epih/e2014038.

37. Leischnig, A.; Henneberg, S.C. Thornton, S.C. Net versus combinatory effects of firm and industry antecedents of sales growth. J. Bus. Res. 2016, 69, 3576-3583. https://doi.org/10.1016/j.jbusres.2016.01.005.

38. Veríssimo, J.M.C. Enablers and restrictors of mobile banking app use: A fuzzy set qualitative comparative analysis (fsQCA). J. Bus. Res. 2016, 69, 5456-5460, https://doi.org/10.1016/j.jbusres.2016.04.155.

39. Lorencova, R. Religiosity and spirituality of alcohol and marijuana users. Journal of Psychoactive Drugs 2011, 43, 180-187. https://doi.org/10.1080 /02791072.2011.605650.

40. Yeterian, J. D., Bursik, K., \& Kelly, J. F. “God put weed here for us to smoke”: a mixed-methods study of religion and spirituality among adolescents with cannabis use disorders. Substance Abuse, 2018, 39, 484-492. https://doi.org/10.1080/08897077.2018.1449168.

41. Pappas, I. O., Woodside, A. G. Fuzzy-set Qualitative Comparative Analysis (fsQCA): Guidelines for research practice in Information Systems and marketing. International Journal of Information Management 2021, 58, 102310. https://doi.org/10.1016/j.ijinfomgt.2021.102310.

42. Planet Youth. https://www.ucd.ie/issda/t4media/PY\%20 Questionnaire\%20English\%20Ireland\%202018\%20HQ.pdf [Consulted at 2019, January 30 $0^{\text {th }}$.

43. DiStefano, C.; Zhu, M.; and Mîndrilã, D. Understanding and Using Factor Scores: Considerations for the Applied Researcher," Practical Assessment, Research, and Evaluation 2009, 14, https://doi.org/10.7275/da8t-4g52.

44. Ragin, C. User's Guide to Fuzzy-Set/Qualitative Comparative Analysis 3; Department of Sociology, University of California: Irvine, CA, USA, 72. 2018.

45. Mendel, J. M., \& Korjani, M. M. Charles Ragin's fuzzy set qualitative comparative analysis (fsQCA) used for linguistic summarizations. Information Sciences 2012, 202, 1-23. https://doi.org/10.1016/j.ins.2012.02.039.

46. Thiem, A. Set-relational fit and the formulation of transformational rules in fsQCA. Compasss Wp Ser. 2010 2010- 61. Available on-line: http://www.compasss.org/wpseries/Thiem2010.

47. McFadden, D. Quantitative Methods for Analyzing Travel Behaviour of Individuals: Some Recent Developments, No 474, Cowles Foundation Discussion Papers, Cowles Foundation for Research in Economics, Yale University, USA. 1977. https://EconPapers.repec.org/RePEc:cwl:cwldpp:474. 